\title{
Sago pith meal based diets in sheep containing different sources of nitrogen: feed preparation, growth performance, digestibility and carcass quality
}

\begin{abstract}
The present research work was designed to evaluate sago pith meal (SPM) as feed for ruminants. A particle size distribution (Experiment 1) was determined in SPM prepared from sago logs by use of three different rasping sizes (large, medium and small). The large rasping produced a negligible amount of fine particles and a large amount of large particles, while small rasping produced a negligible amount of large particles and a smaller amount of fine particles than the medium rasping. Since both large and fine particles are not desirable, the SPM produced by the small rasping was considered the best as feed for ruminants and was used in two experiments with sheep (Experiments 2 and 3) to determine the digestibility and growth performance/carcass quality, respectively. Sheep were divided in each experiment into three treatments and each group was fed one of three SPM based diets: (1) control diet (CNT) contained SPM and soybean meal, (2) USM diet contained SPM, soybean meal and urea, while (3) UFM diet contained SPM, fish meal and urea. In the Experiment 2, the digestibility of dry matter was not different $(\mathrm{P}>0.05)$ among the diets, but the digestibility of neutral detergent fiber was lower $(\mathrm{P}<0.05)$ for the USM and UFM diets than for the CNT diet. However, there was no difference $(\mathrm{P}>0.05)$ between the USM and UFM diets. In Experiment 3, the means for the average daily gain, feed intake, carcass weight, dressing percentage and lean meat were not different $(\mathrm{P}>0.05)$ between the USM and UFM diets, but all were higher $(\mathrm{P}<0.05)$ for the CNT diet than for both the USM and UFM diets. It was concluded that the small rasping is best for preparation of SPM as feed for ruminants, and that a highly soluble and rumen degradable protein supplement is more efficient than urea to support the maximum microbial growth in the rumen of sheep fed diets based on SPM supplemented with soybean meal or fish meal.
\end{abstract}

Keyword: Sago pith meal; Rasping size; Sheep growth; Carcass quality; Digestibility 